\title{
Advanced Investigation of Remote Sensing to Geological Mapping of Zefreh Region in Central Iran
}

\author{
Reza Mohammadizad, Ramin Arfania \\ Department of Geology, Isfahan (Khorasgan) Branch, Islamic Azad University, Isfahan, Iran \\ Email: reza.smz@gmail.com,rarfania@gmail.com
}

How to cite this paper: Mohammadizad, R. and Arfania, R. (2017) Advanced Investigation of Remote Sensing to Geological Mapping of Zefreh Region in Central Iran. Open Journal of Geology, 7, 1509-1529. https://doi.org/10.4236/ojg.2017.710101

Received: August 30, 2017

Accepted: October 17, 2017

Published: October 20, 2017

Copyright $\odot 2017$ by authors and Scientific Research Publishing Inc. This work is licensed under the Creative Commons Attribution International License (CC BY 4.0).

http://creativecommons.org/licenses/by/4.0/

\begin{abstract}
This study has tried to prove the ability of remote sensing techniques to extract information necessary for preparation of geological mapping of the earth's surface using multi-spectral satellite images which are rich sources of Earth's surface information. In this study, the surface geological mappings of Zefreh region have been investigated through ASTER, OLI, and IRS-PAN remote sensing data. To prepare the geological map, preprocessing steps and reducing noises from data using MNF algorithm were firstly carried out. Then a set of processing algorithms and image classification methods are included; the band rationing, color composite and pixel classification based on maximum likelihood, spectral and sub-pixel classification methods of spectral angle mapper (SAM), spectral feature fitting (SFF), linear spectral differentiation (LSU), hill-shade images and automatic lineament extraction were used. Confusion matrix was formed for all classified images through control points were randomly selected from 1:25,000 map of the region to determine the accuracy of obtained results, which indicated the maximum accuracy (up to 90\%) of output images. Comparing the results obtained from these methods with the map prepared by ground operations confirmed accuracy results. Finally, the surface geology and fault map of Zafreh region was produced by combining detected geological formations and tectonic lineaments.
\end{abstract}

\section{Keywords}

Zefreh, Remote Sensing, Image Processing, Geological Mapping,

Classification, Overall Accuracy

\section{Introduction}

Zefreh region is located on the Uremia-Dokhtar volcanic belt. Geology of the re- 
gion includes consists of the igneous, sedimentary and metamorphic. Various types of igneous rocks including tonalite, gabbro and diorite have infiltrated to the region during cutting-bending development of Qum-Zefreh fault system. The adjacent sedimentary rocks with intrusive masses has caused metamorphism in the region [1] Figure 1. This article studying on an area with complex geology to show the ability of remote sensing Images in creating Geological maps with good overall accuracy in comparing with the result of 1:25,000 map created with filed operations lately. To reach this goal a collection of remote sensing data with different spectral and spatial resolutions was processed in an Image processing algorithm complex in the form of flowchart Figure 2. The traditional ways of preparing geological maps are very time consuming and costly. In the event that remote sensing provides a variety of satellite images with different spatial and spectral resolutions with fast and easy access which the matter has increased the ability of this technology to detect accidents and natural disasters and planning for large-scale actions. Phenomena selectivity absorbs and reflect electromagnetic energy differently based on their different surface molecular

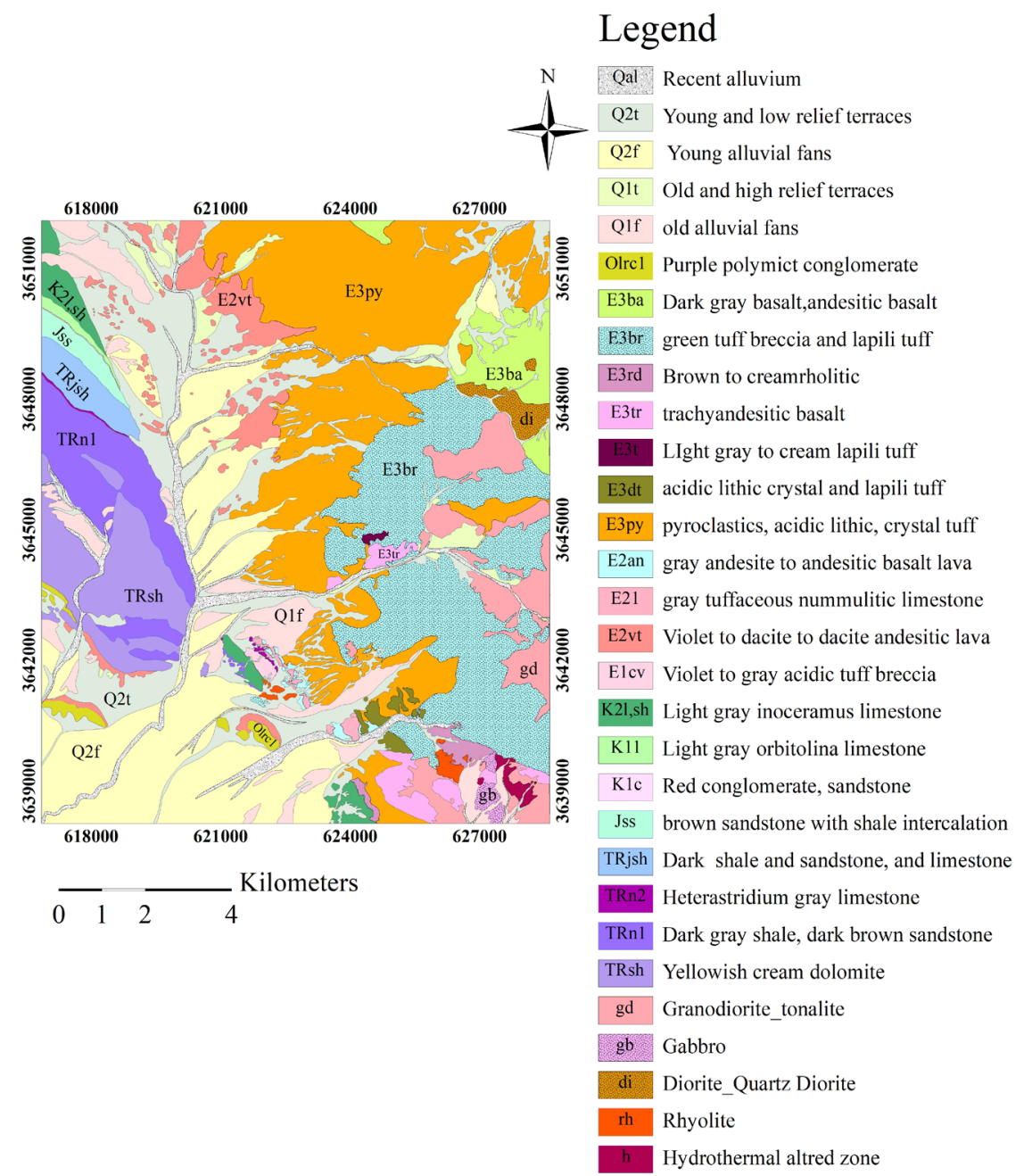

Figure 1. 1:25,000 Geological map of Zefreh [1]. 


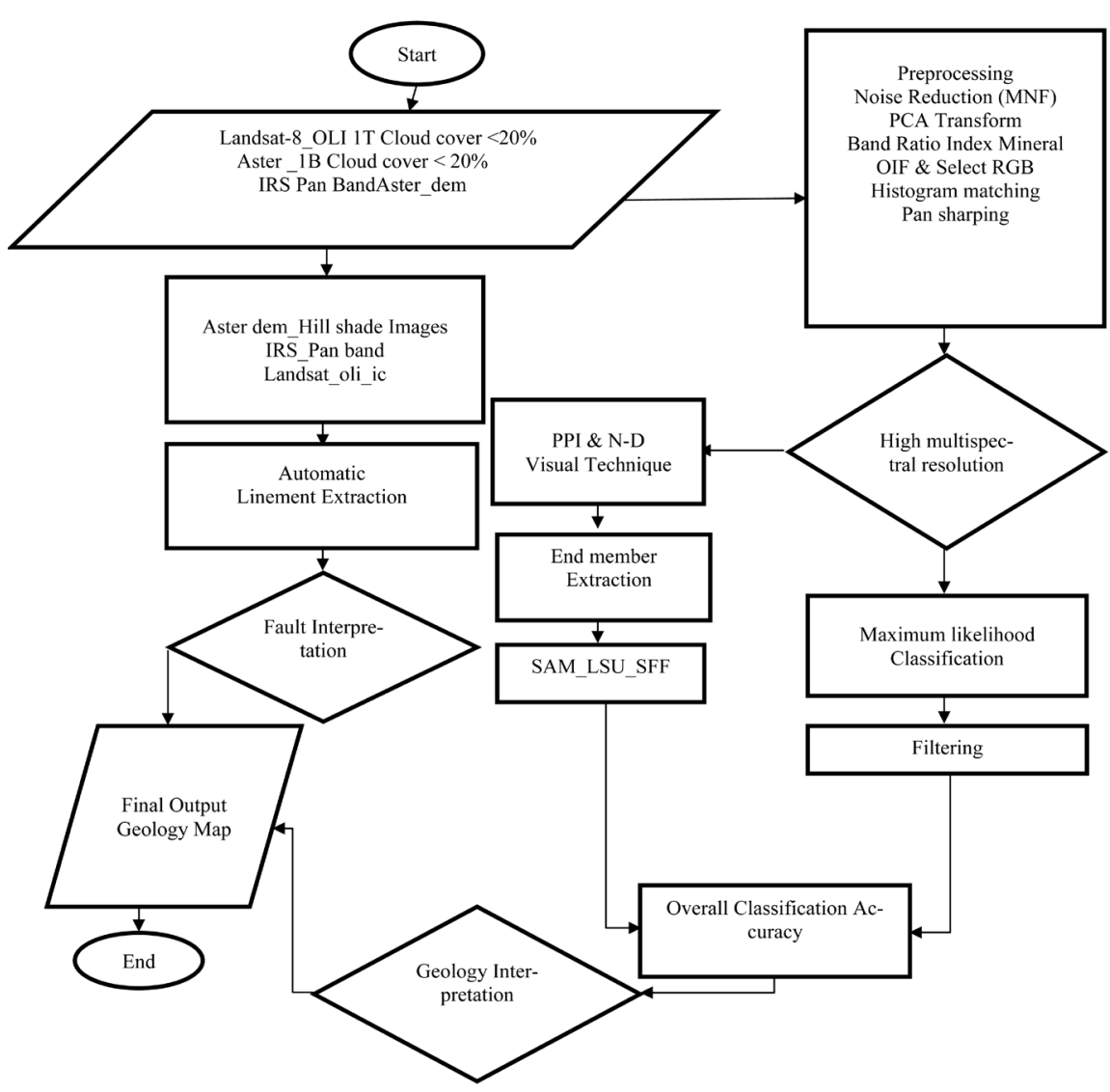

Figure 2. The flowchart of processing and data integration for geological mapping.

compound. Texture, pattern, color tone and geological concept are among the most useful features for identifying lithological units in remote sensing images. All of these features lead to creation of different spectral absorption characteristics (the spectral signature curve) [2]. The brightness of each pixel is expressed as a number and its position inside the image is identified based on its row and column number. A cell includes one or several dark and light phenomena based on the area which it covers. Only one digit is recorded for a pixel which is the brightness grade average of total of the phenomena. As a result, details inside the pixels are not expressed and pixels are considered pure and hence, any pixel belongs to a certain class. It is while that in sub-pixel classification methods, not only a pixel can be placed in more than one class but also there is no obligation for the number of classes to place combined pixels in them. The matter has led that a set of processing and classification methods of basic pixel, spectral and sub-pixel is used to extract maximum information about available images [3].

The study region is one of the rural district of Isfahan city which is located at 75 kilometers distance of North East of Isfahan with 52 degrees and 15 minutes of longitude and 33 degrees latitude in the upper left point and 52 degrees and 23 minutes and 30 seconds of longitude and 45 minutes of longitude in the lower right point. Zefreh village located in a mountainous area and its height from sea level is 2070 meters. 


\section{Materials and Methods}

In present study, the images of ASTER, LANDSAT8-OLI sensors and IRS single panchromatic band sensor have been used for create a geological map of the study area. ASTER sensor covers a wide spectral range with high spatial resolution by 14 bands from visible wave length to thermal infrared. In present study, B1 data of ASTER sensor has been used which is Geo referenced, but has CROSSTALK error. The error is created due to the light scattering by detector of Band 4 which the impacts of this noise are removed from the image using Crosstalk Software (ccs). To remove atmospheric effects from the used data, FLAASH Atmospheric Correction was applied on the data using ENVI software [4]. LANDSAT8 satellite is equipped with two sensors (OLI operational land imaging sensor and TIRS infrared thermal sensor). These two sensors gather data on 9 short-wave bands and 2 thermal wavelength bands. The bands of OLI sensor of this satellite were used in present study. Radiometric and atmospheric corrections were applied on the data using ENVI 5.02 Software. The used image was Geo referenced due to utilizing level T1 of LANDSAT8 products and there was no need to geometric correction [5].

The IRS-PAN image with spatial resolution of 5.7 meter was also used as high-resolution spatial data for creating pan sharp images and for linement extraction operation.

The general schema of operation set performed on the input data that includes the preprocessing steps, the image processing methods, the accuracy calculation of the classified images and merging output images for creating final geological map, are shown in the flowchart of Figure 2. The Images processing algorithms used in this study have been selected based on the spatial and spatial power of the input data. In continue, the performance of each of these algorithms has been discussed.

\section{Image Processing Algorithms}

Minimum Noise Fraction Algorithm (MNF algorithm) is based on two consecutive operations [6]. The first step is based on estimating the level of noise in data and shown by a correlation matrix. The second step is related to calculations for measuring correlation in data. In this step, several data packages are created including weighted data on standard deviation in raw data. Since all bands are participated in weighting each of the produced data package, the algorithm keeps the general information of data. Most of data related to the difference in earth surface effects are saved in the first data packages and the last packages include noises [7]. The performance of Principal component analysis algorithm (PCA algorithm) defines satellite data on a new axis based on their frequency. The main component of this analysis is data integration with a high variance in the first few components and the next components mostly include noises [8].

The images of band ratio are used to display spectral contrast of certain spectral aspects. Therefore, the method can be used to separate rock units from each 
other. Another advantage of images' separation is to remove or reduce adverse effects resulting from exposure changes such as topography effects [9] [10].

The best reference to create a False Color Composite is spectral signature curve of targets, but as much as the number of sensing bands can help. Since non-visible bands are also used in color combination, the natural color of objects are not observed in produced image, but it would be easier to detect the effects in this status of real scheme by knowing the exact arrangement of assignment bands and how behave the effects in these bands [11]. The method of determining the optimum index factor is used to select the best Tri-band color combination. The coefficient of optimum index depends on to two parameters of variance and correlation coefficient of bands in the band combination.

The main advantage of maximum likelihood classification method is to take into account changes of each class in classifying the considered pixel using covariance matrix. The method relies on the assumption that data of each used band as input of algorithm have normal distribution and it is only need to select a number of pixels to correctly estimate the mean vector and covariance-variance matrix [12]. The technique classifies each pixel of satellite image only in a single class based on its features [13].

A pure pixel is one which covers a region with the same material on a wider area of a sensing pixel's size and provides a spectral profile of a certain event (effect) the Earth surface [6]. Pixel purity index (PPI) image is formed in a way that the value of each pixel is equal to the number of times it has been sharply recorded. In fact, the algorithm separates purer pixels from mixed ones. The PPI technique is applied on the output of MNF algorithm in which bands with noise have been removed [14].

In Spectral angle mapper (SAM) method, each spectrum is considered corresponding to the vector in a space with dimensions equal to the number of bands. This method is not sensitive to the brightness of the pixel and the algorithm of indicating spectral angle calculates the similarity between a spectrum of pure member $(\mathrm{T})$ and a reference spectrum $(\mathrm{R})$ for $\mathrm{N}$ bands of Arc sinus point index of two spectrums as like equation of Equation (1) [15].

$$
A=\sum_{t=1}^{n} t_{i} / \sqrt{a \sum_{t=1}^{n} t_{i}^{2} \sum_{t=1}^{n} t_{i}^{2}}
$$

Therefore its output for each pixel is the angular distance between two spectrums which expressed in radians and varies from 0 to $\Pi / 2$. Therefore the spectrum with lowest angle to the pure member would be the most similar spectrum [16].

The narrowest spectral range including the total of absorption features are used to obtain most accurate results from SFF classification. It would be possible to obtain the best accordance (fitness) with the minimum error by separating an absorption feature. To conduct SFF, the reference spectrum must be firstly extracted form an image or a spectral library and then the statistical sequence of data must be removed [17]. Therefore, the results of SFF include a scaling image 
and a RMS image or a combined fit image (scale/RMS) to each reference spectrum. In fact, the image is a sensing from the depth of absorption feature associated with the frequency of considered materials.

Linear spectral unmixing algorithm (LSU) considers the reflected energy from each pixel as a linear combination of each of the various pure coves' reflections on the surface of that pixel. In fact, the reflections created by each of the pure covers on the surface of each mixed pixel are participated in the linear combination with the weights which are their mixing ratio [18]. The mixing occurs when materials with different spectral features presented in a pixel of image [19]. The algorithm finds the relative or absolute frequency of a number of spectral combinations or end members. The pure spectral result is a series of gray scale images for each end member and the error image of Root Mean Square [18] [20].

Hill shade images are prepared using DEM or images with high spatial resolution and change in the angle of azimuth and altitude of the sun [21] [22] [23]. The technique is carried out through elevation data and highlighting it and changes in the radiation angle of the sunlight to the Earth' surface which makes lineaments visible in the image. Combining images at the pixel level is the most common level of combining images used to improve image quality to better visual interpretation. In combining images, multi-spectrum images with medium spatial resolution are mostly combined with an image with higher spatial resolution and provide a proper combination to visual interpretation. The resulting color combination involving more spatial details compare to the initial combination of multi-spectrum image.

\section{Results}

The main purpose of present study was to prepare geological mapping through combine the results obtained from algorithms of images' processing and classification. Firstly, the noises of ASTER and LANDSAT8 images were calculated and removed using MNF algorithm. The output of this algorithm was an image with 9 components for ASTER image and 7 components for LANDSAT8 image. The amounts of eigenvalue were studied to select components with higher level of variance among data packages of desired images Table 1. Components 8 and 9 in ASTER-MNF image and components 6 and 7 in LANDSAT8 were removed due to having the lowest value of variance. Figure 3 Represents the spectral diagram of sensing bands of ASTER and LANDSAT8 before and after implementing MNF algorithm.

Principal component Analyze algorithm (PCA) was implemented to create data packages with the least amount of duplicate information. The components were used to produce false color composite to create a lithology separation among data during image analysis.

The images of band ratio were prepared through dividing sensing bands of ASTER using bands of the image with special spectral signature of considered rock units which had been prepared to create separation Table 2 . The band ratios $(\mathrm{B} 6+\mathrm{B} 8) / \mathrm{B} 7)$ were used to separation of carbonate and dolomite units. The 
Table 1. The table related to values of STDV and EIGENVALUE for data of ASTER and LANDSAT8.

\begin{tabular}{ccccc}
\hline \multirow{2}{*}{$\begin{array}{c}\text { Basic } \\
\text { Stats }\end{array}$} & St.dev & Eigenvalue & St.dev & Eigenvalue \\
\cline { 2 - 5 } ASTER & ASTER & LANDSAT8 & LANDSAT8 \\
\hline Band 1 & 12.29142 & 151.0790 & 5.943570 & 35.326022 \\
Band 2 & 4.080752 & 16.65253 & 3.808131 & 14.501860 \\
Band 3 & 2.411722 & 5.816402 & 3.560191 & 12.674959 \\
Band 4 & 2.134372 & 4.555546 & 3.092045 & 9.560744 \\
Band 5 & 2.001360 & 4.005441 & 2.380144 & 5.665088 \\
Band 6 & 1.794125 & 3.218886 & 2.312117 & 5.345887 \\
Band 7 & 1.525973 & 2.328593 & 1.230228 & 1.513460 \\
Band 8 & 1.479495 & 2.188906 & - & - \\
Band 9 & 1.396923 & 1.951395 & - & - \\
\hline
\end{tabular}

Table 2. The band ratios applied on bands of ASTER image.

\begin{tabular}{|c|c|c|c|c|}
\hline Features & Band or Ratio & Comment & Reference & Features \\
\hline $\begin{array}{l}\text { Ferrous Silicates } \\
\text { (biotit, chl, amph) }\end{array}$ & $5 / 4$ & & $\begin{array}{c}\text { Fe oxide, } \mathrm{Cu}-\mathrm{Au} \\
\text { Alteration }\end{array}$ & CSIRO \\
\hline Dolomite & $(6+8) / 7$ & & Carbonates & Rown, USGS \\
\hline Quartz Rich Rocks & $14 / 12$ & & Silica & Rown \\
\hline NDVI & $(3-2) /(3+2)$ & & Vegetation Index & \\
\hline
\end{tabular}

ratio of 5/4 was used to make visible the Ferro silicate areas. The ratio of 12/14 (thermal bands of ASTER sensor) was used to extract areas rich in quartz. In addition, NDVI formula was used to prepare gray scale image which indicated regions covered with vegetation.

The false color composite technique was also applied on remote sensing data using band ratios to create lithology separation in the region Table 3. The OIF index was applied on the images of LANDSAT8 and ASTER to select the best falsecolor composite which its results have been presented in Table 4 and Table 5. The best false color composite for ASTER data was created using band composite of RGB = 731 Figure 4, which had the highest level of frequency and lowest amount of duplicate information among color composites can be prepared from ASTER image sensing. The false color composite of Abdolsalam at the ratios of 12/14, 3/1 and 4/1was applied on the ASTER image sensing to create lithology separation to identify Dolomitic units, Ferro silicate and quartz-rich regions of the west sedimentary units of under study region Figure 5. Figure 6 represents the false color composite (RGB $=761$ ) which has been prepared from bands of LANDSAT8 image and utilizes from the highest level of OIF index. In the Vander Mir false color composite has been prepared from band ratios of $\mathrm{RGB}=(\mathrm{B} 6 / \mathrm{B} 7, \mathrm{~B} 4 / \mathrm{B} 2$, and $\mathrm{B} 3)$ of LANDSAT8 data, the E3PY unit is observable 


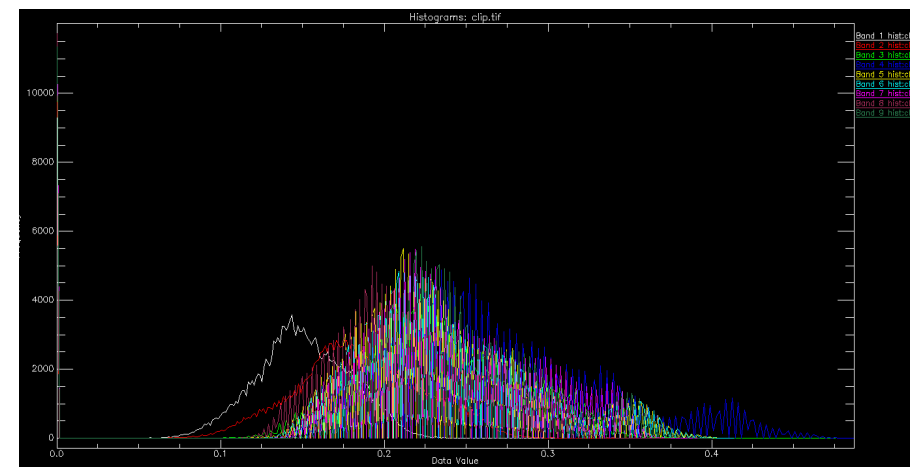

(a)

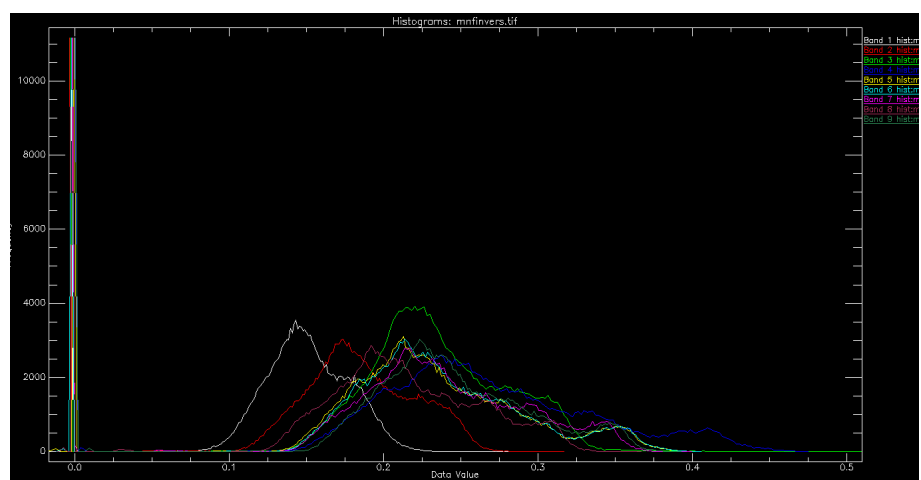

(b)

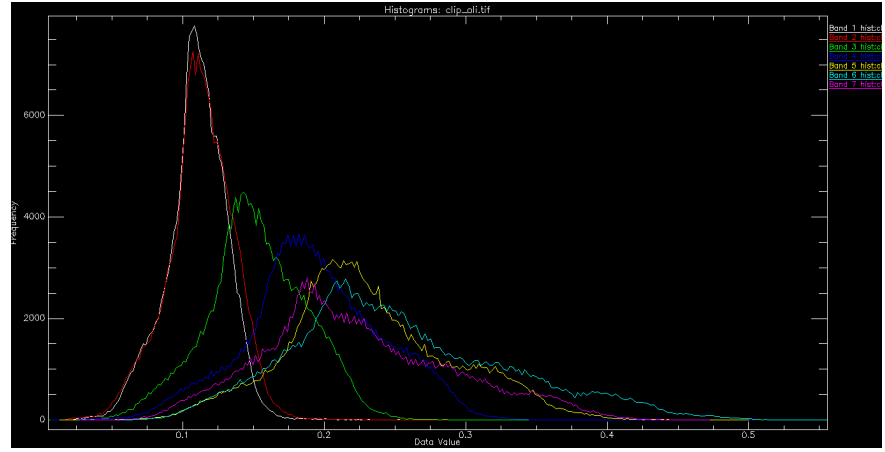

(c)

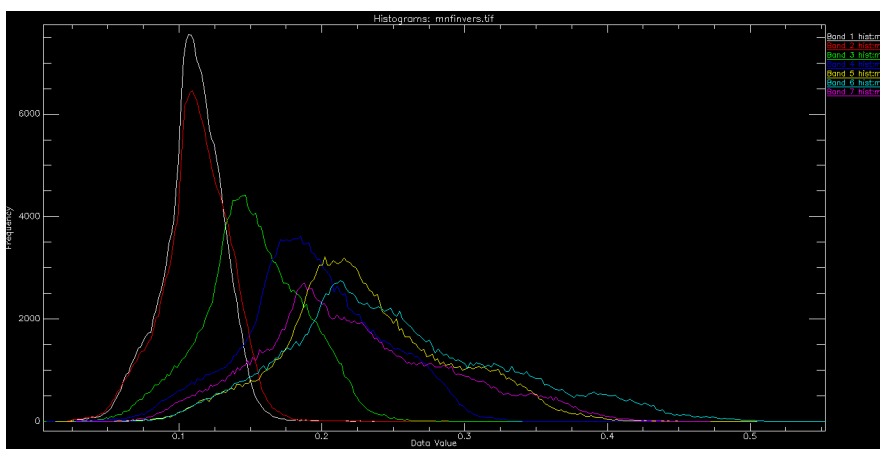

(d)

Figure 3. (a) spectral diagram of ASTER data before implementing MNF; (b) spectral diagram of ASTER data after implementing MNF; (c) spectral diagram of LANDSAT8 data before implementing MNF; (d) spectral diagram of LANDSAT8 data after implementing MNF. 


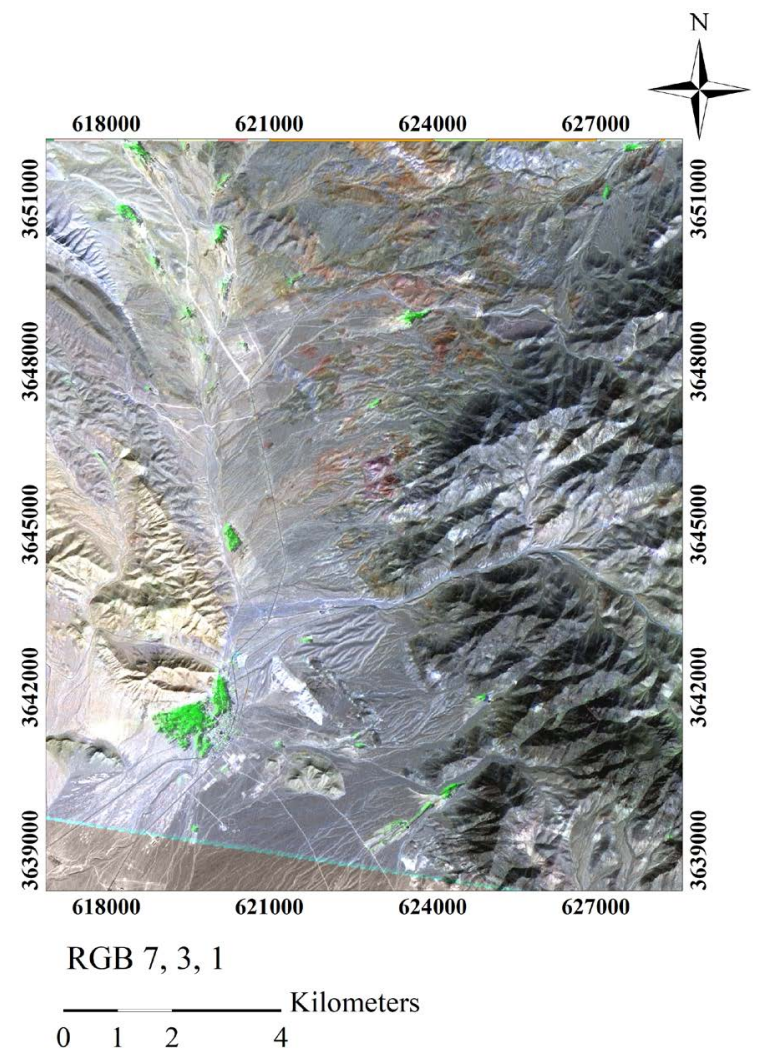

Figure 4. ASTER best OIF color composite.

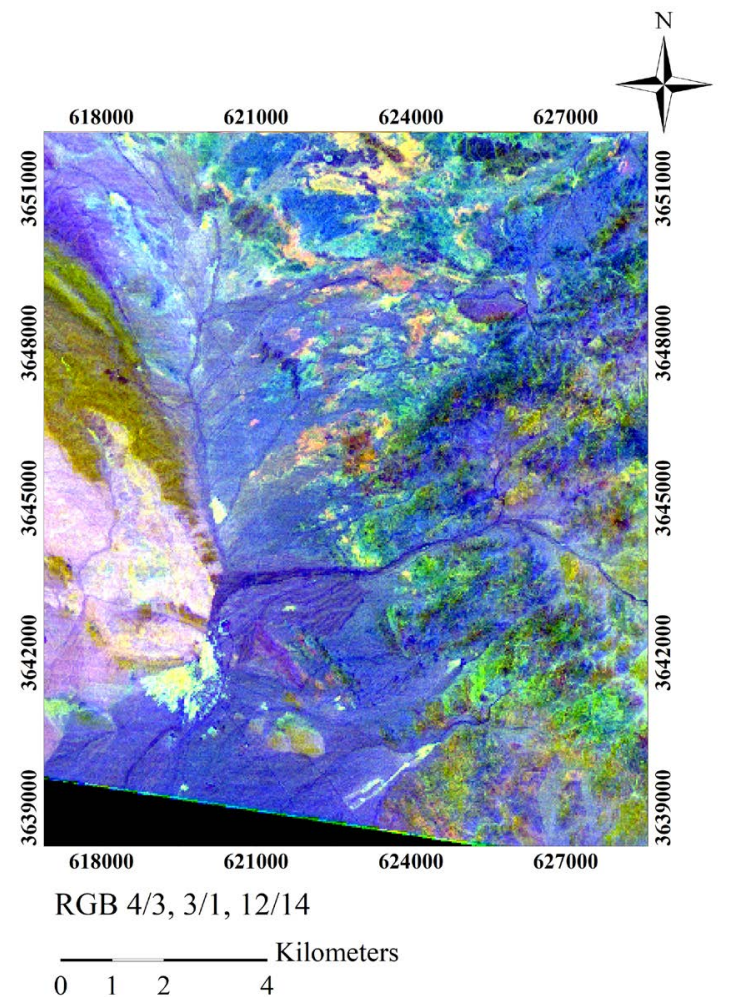

Figure 5. ASTER ABDALSALAM color composite for lithological mapping. 


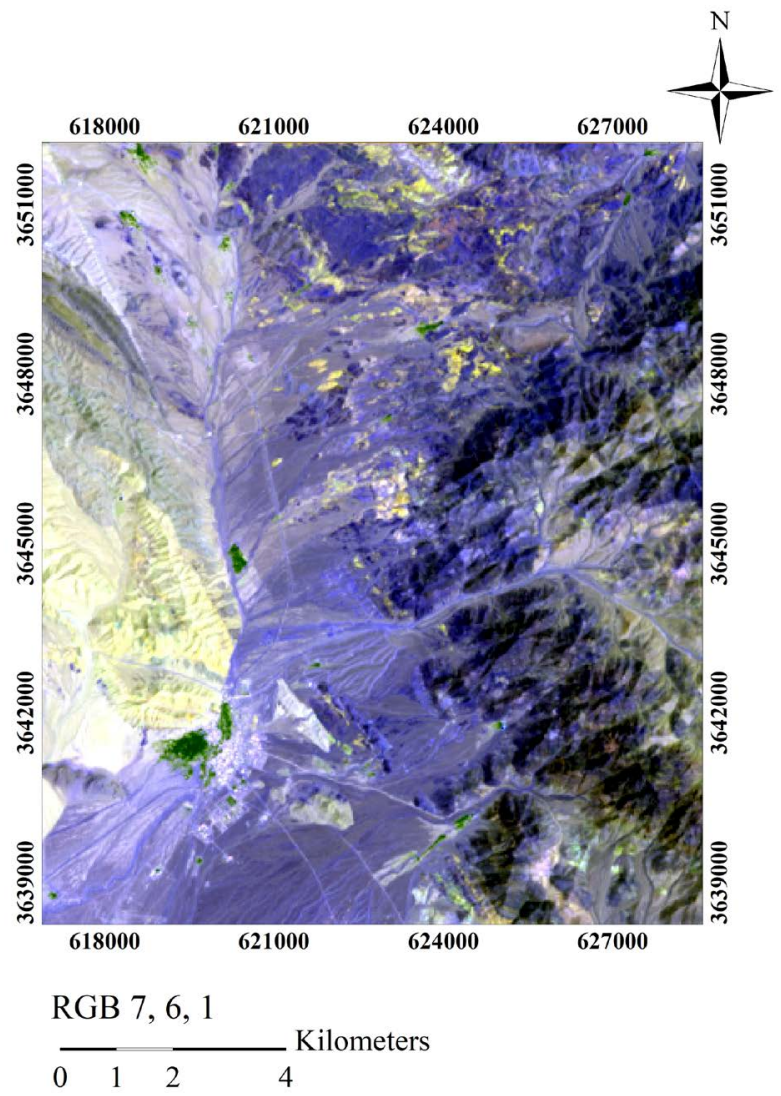

Figure 6. LANDSAT8 best OIF color composite.

Table 3. The produced false color composite using data of ASTER and LANDSAT8 to create lithology separation.

\begin{tabular}{|c|c|c|c|c|}
\hline \multirow{2}{*}{ Enhancement } & Red & Green & Blue & Reference \\
\hline & ASTER & & & \\
\hline Silica, $\mathrm{Fe}^{2+}$ & $14 / 12$ & $(1 / 2)+(5 / 3)$ & MNF Band1 & Rown (usgs) \\
\hline \multirow[t]{2}{*}{$\begin{array}{l}\text { Discrimination for } \\
\text { Mapping }\end{array}$} & $4 / 1$ & $3 / 1$ & $12 / 14$ & Abdel Salam \\
\hline & & LANDSAT8_OL & & \\
\hline $\begin{array}{l}\text { Discrimination for } \\
\text { Mapping }\end{array}$ & $\mathrm{b} 6 / \mathrm{b} 7$ & $\mathrm{~b} 5 / \mathrm{b} 4$ & $\mathrm{~b} 4 / \mathrm{b} 2$ & ABRAMS \\
\hline $\begin{array}{l}\text { Discrimination for } \\
\text { Mapping }\end{array}$ & $\mathrm{b} 6 / \mathrm{b} 4$ & $\mathrm{~b} 6 / \mathrm{b} 2$ & $\mathrm{~B} 6 / \mathrm{B} 7$ & GAD \& KUSKY \\
\hline $\begin{array}{l}\text { Discrimination for } \\
\text { Mapping }\end{array}$ & $\mathrm{b} 7 / \mathrm{b} 6$ & $\mathrm{~b} 6 / \mathrm{b} 5$ & $\mathrm{~b} 4 / \mathrm{b} 2$ & GAD \& KUSKY \\
\hline $\begin{array}{l}\text { Discrimination for } \\
\text { Mapping }\end{array}$ & $\mathrm{b} 6 / \mathrm{b} 7$ & $\mathrm{~b} 4 / \mathrm{b} 2$ & $\mathrm{~B} 4 / \mathrm{B} 6$ & SABIN \\
\hline $\begin{array}{l}\text { Discrimination for } \\
\text { Mapping }\end{array}$ & $\mathrm{b} 6 / \mathrm{b} 7$ & $\mathrm{~b} 4 / \mathrm{b} 2$ & B6 & VANDERMEER \\
\hline
\end{tabular}

from bright green to dark green ranges. In addition, some parts have been distinguished with dark blue and little parts with orange color. The E3BR and E3BA which indicate igneous lithology with ultra-basic and probably serpentinized 
Table 4. The table of OIF index for ASTER data.

\begin{tabular}{ccccc}
\hline $\begin{array}{c}\text { OIF Index Highest } \\
\text { Ranking }\end{array}$ & & & & \\
\hline $1:$ & $\mathrm{b} 7$ & $\mathrm{~b} 3$ & $\mathrm{~b} 1$ & $(74.02)$ \\
$2:$ & $\mathrm{b} 4$ & $\mathrm{~b} 3$ & $\mathrm{~b} 1$ & $(73.67)$ \\
$3:$ & $\mathrm{b} 7$ & $\mathrm{~b} 4$ & $\mathrm{~b} 1$ & $(73.50)$ \\
$4:$ & $\mathrm{b} 9$ & $\mathrm{~b} 3$ & $\mathrm{~b} 1$ & $(73.37)$ \\
$5:$ & $\mathrm{b} 4$ & $\mathrm{~b} 2$ & $\mathrm{~b} 1$ & $(72.90)$ \\
\hline
\end{tabular}

Table 5. The table of OIF index for LANDSAT8 data.

\begin{tabular}{ccccc}
$\begin{array}{c}\text { OIF Index Highest } \\
\text { Ranking }\end{array}$ & & & & \\
\hline $1:$ & $\mathrm{b} 7$ & $\mathrm{~b} 6$ & $\mathrm{~b} 1$ & $(71.58)$ \\
$2:$ & $\mathrm{b} 6$ & $\mathrm{~b} 5$ & $\mathrm{~b} 1$ & $(71.40)$ \\
$3:$ & $\mathrm{b} 7$ & $\mathrm{~b} 5$ & $\mathrm{~b} 1$ & $(71.04)$ \\
$4:$ & $\mathrm{b} 7$ & $\mathrm{~b} 6$ & $\mathrm{~b} 2$ & $(70.03)$ \\
$5:$ & $\mathrm{b} 6$ & $\mathrm{~b} 2$ & $\mathrm{~b} 1$ & $(69.98)$ \\
\hline
\end{tabular}

combinations are observable with red color. The units of Naiband formation are observed with pink color and composites of yellow color. Intrusive units and water bodies are observable with yellow and ink red colors, respectively Figure 7. B7/B6 Gad and Kusky color composite created by band ratios of LANDSAT8 (4/2, 6/5 and 7/6) shows Serpentinized units with color of red-black and met volcanic units are also observable in the image with a color range of green to yellow. In the image, dolomitic areas have been distinguished with green-blue and limestone areas with blue and dark-orange Figure 8. B6/B4 Gad and Kusky color composite with band ratios of LANDSAT8 (B6/B4, B6/B2 and B7/B6) was created which indicates Serpentinized rock units with dark color (blue-black) and the around met volcanic units with pink. In the image, the dolomitic areas are also observable with light yellow Figure 9.

The technique of pixel purity index was applied on sensing image of ASTER with PPI ITERATIONS: 5000 and THRESHOULD VALUE: 2.5,000 using ENVI5.02 Software to identify pure pixels. Then ASTER-MNF data were used in the $\mathrm{N}$-dimensional visualer to classify the material of pure pixels of the image. The extracted pure pixels were used for sampling rock units to perform classification methods of SAM, SFF and LSU. These three methods were used to classify Sedimentary units located in west part of study region in 4 different classes to have a proper criterion of comprising classification accuracy (Figure 10).

LANDSAT8 image was used to perform maximum likelihood classification method. Firstly the training samples were prepared at ARC GIS10.2 environment to select classes from map of the study area and available satellite images of Zefreh region which were overlaid and geo-referenced. The samples were clus- 


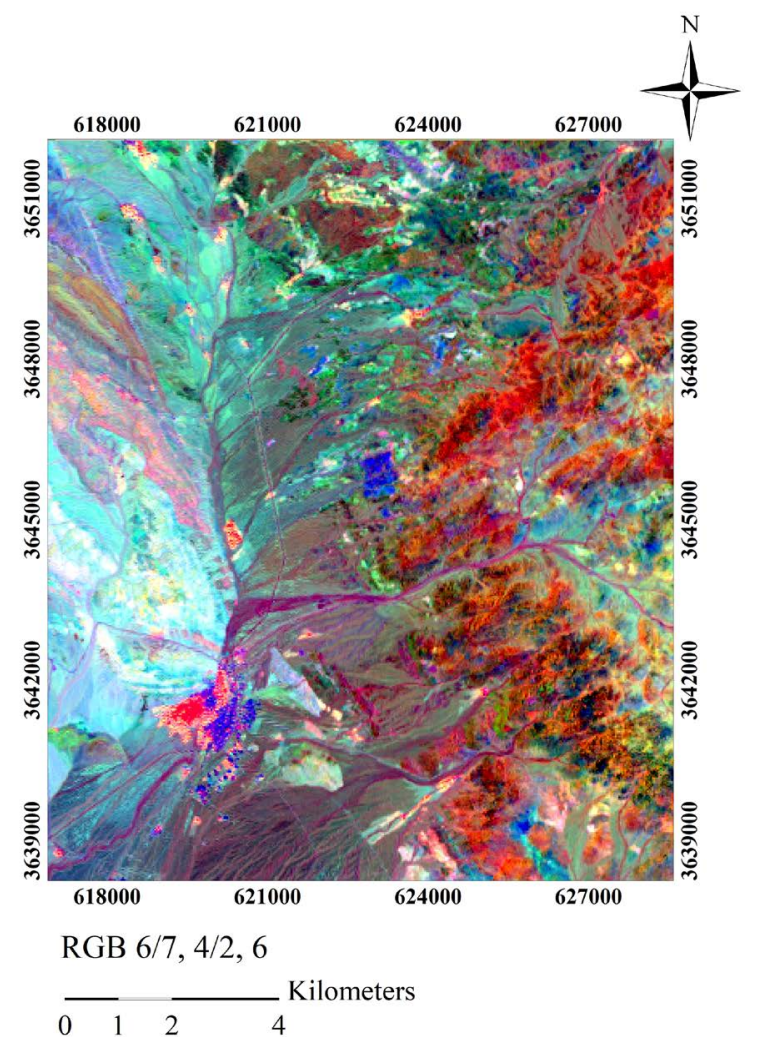

Figure 7. LANDSAT8 VAN DER MEER color composite for lithological mapping.

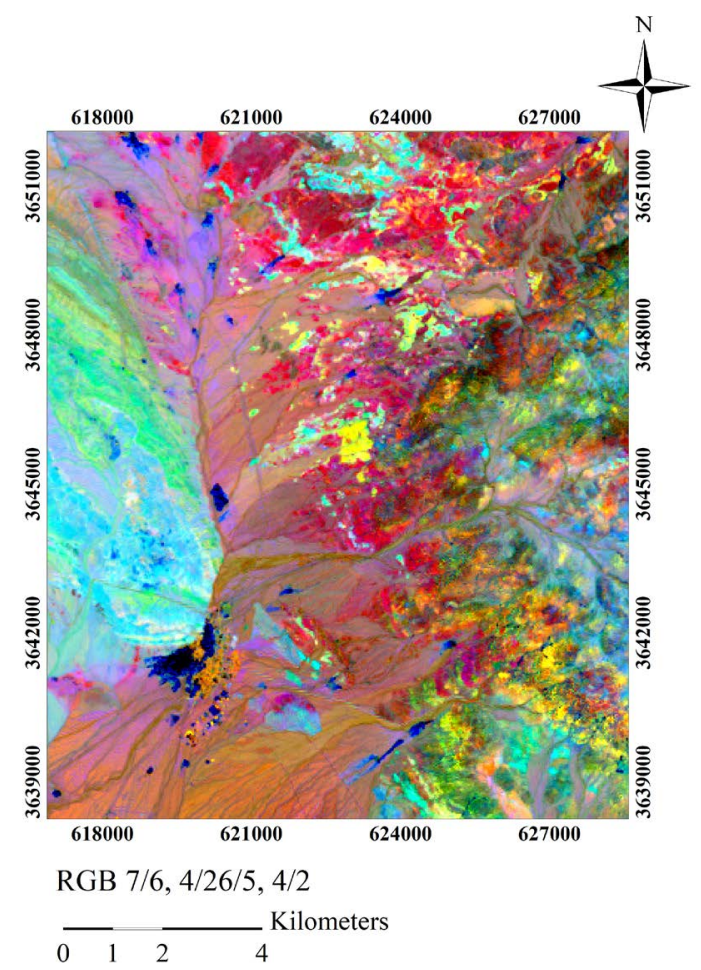

Figure 8. LANDSAT8 GAD \& KUSKY_1 color composite for lithological mapping. 


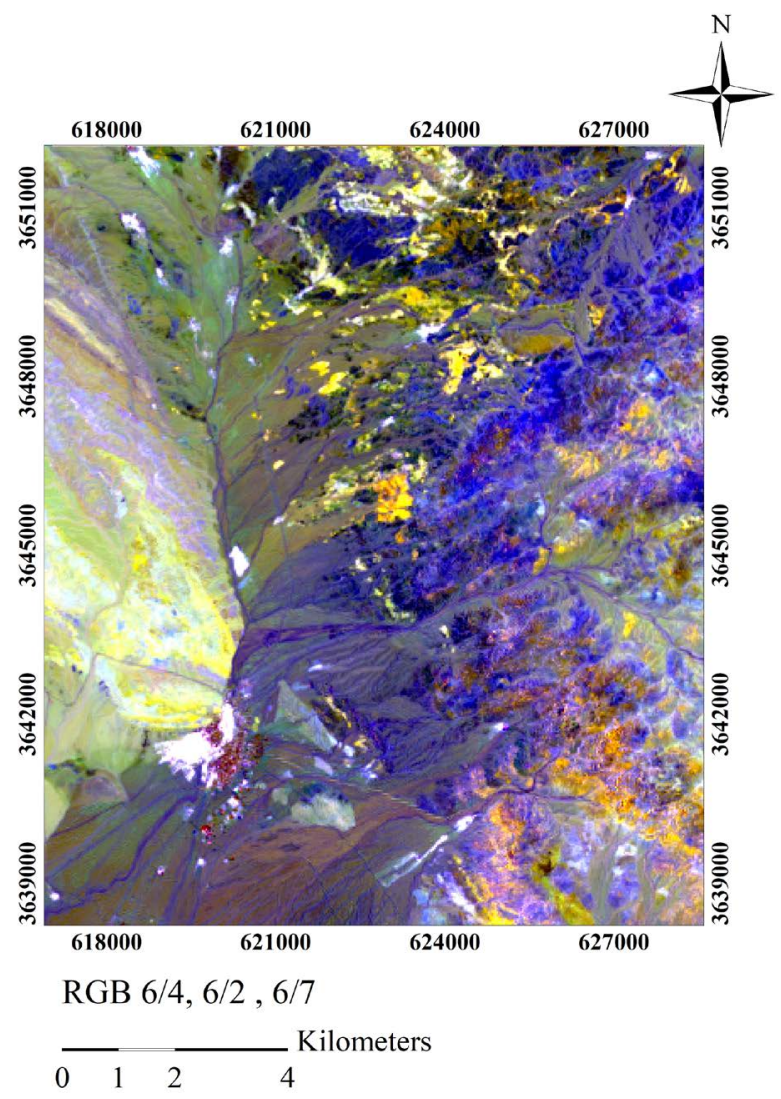

Figure 9. LANDSAT8 GAD \& KUSKY_2 color composite for lithological mapping.
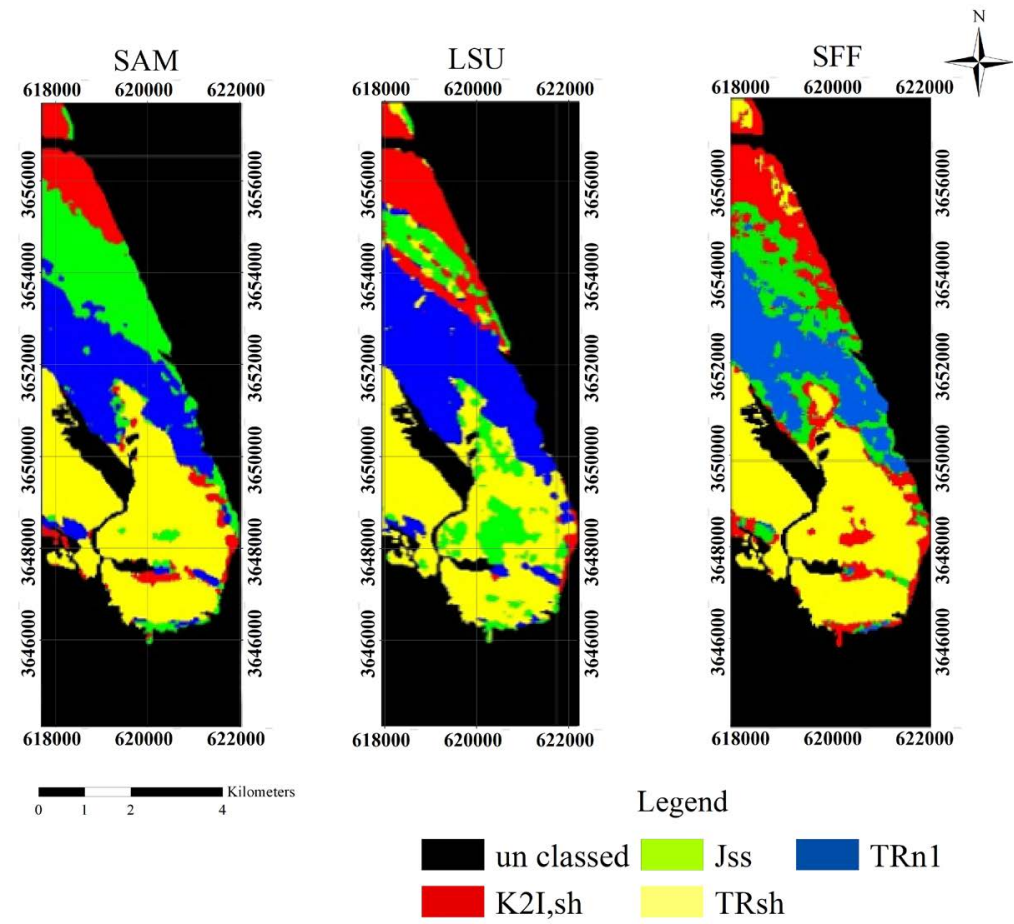

Figure 10. Rule image classification for calculating accuracy of spectral base classifier methods. 
tered in 8 classes. Then the algorithm of maximum likelihood classification was applied on the image using ENVI 5.02 Software.

Then, MAJOORITY filter was applied on the classified image to create more uniformity in produced classes Figure 11. THE output classified images produced by SAM, SFF, LSU and maximum likelihood classification methods, used for calculating Confusion to determine the accuracy of classified images. A number of control points were determined to each class which each of the classes of classified images was comprised with them. The obtained results indicate the maximum overall accuracy. The accuracy level of 95\% and Kappa coefficient of 0.943 were obtained for maximum likelihood basic pixel classification. Also, the overall accuracy of $86.25 \%$ and Kappa coefficient of 8167 obtained to spectral feature fitting classification.

The overall accuracy of $90 \%$ and Kappa coefficient of 0.9667 obtained for classification of LSU basic pixel and the maximum overall accuracy level of $97.5 \%$ and Kappa coefficient of 0.9667 were obtained for classification of basic spectrum of spectral angle mapper. Table 6 presents the related statistics to the algorithm of determining accuracy on the classified images.

SFF overall accuracy $=(69 / 80) 86.25000 \%$ SFF kappa coefficient $=0.8167$

LSU overall accuracy $=(72 / 80) 90.0000 \% \_L S U$ kappa coefficient $=0.8667$

To automatically prepare the Lineaments map of the region, two Hill-shades images which generated by combining several hill-shade images were used alongside the PAN band of IRS and LANDSAT8-IC1 as inputs of GEOMATICA

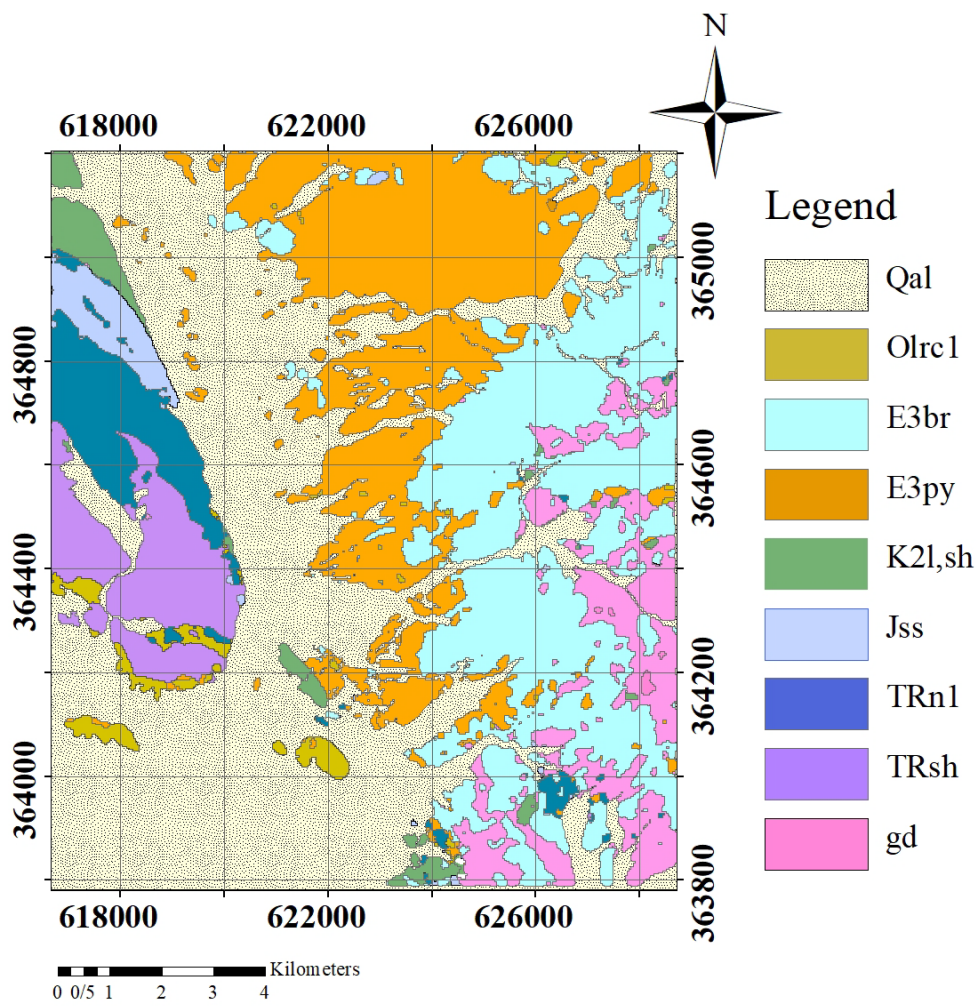

Figure 11. Maximum likelehhod classification with LANDSAT-8 data. 
Table 6. (a) SFF_ground truth (pixels); (b) SFF_accuracy; (c) LSU_ground truth (pixels); (d) LSU_accuracy; (e) SAM_ground truth(pixels); (f) SAM_accuracy; (g) Maximum likelehood Classification_ground truth (pixels); (h) Maximum likelehood Classification_ accuracy.

(a)

\begin{tabular}{cccccc}
\hline CLASS & K2.ISH & TRN1 & TR.JSS.1 & TRSH & Total \\
\hline Un clasified & 0 & 0 & 0 & 0 & 0 \\
K2.ISH & 15 & 2 & 0 & 3 & 20 \\
TRN1 & 5 & 18 & 0 & 0 & 23 \\
TR.JSS.1 & 0 & 0 & 19 & 0 & 19 \\
TRSH & 0 & 0 & 1 & 17 & 18 \\
Total & 20 & 20 & 20 & 20 & 80 \\
\hline
\end{tabular}

(b)

\begin{tabular}{ccccc}
\hline CLASS & Prod. Acc. & User Acc. & Prod. Acc. & User Acc. \\
\hline K2.ISH & (Percent) & (Percent) & (Pixel) & (Pixel) \\
TRN1 & 75 & 75 & $15 / 20$ & $15 / 20$ \\
TR.JSS.1 & 90 & 78.6 & $18 / 20$ & $18 / 23$ \\
TRSH & 95 & 100 & $19 / 20$ & $19 / 19$ \\
\hline
\end{tabular}

LSU overall accuracy $=(72 / 80) 90.0000 \% \_$LSU kappa coefficient $=0.8667$.

(c)

\begin{tabular}{cccccc}
\hline Class & K2.ISH & TRN1 & TRSH & TRJ.SS.1 & Total \\
\hline $\begin{array}{c}\text { Un } \\
\text { classed }\end{array}$ & 0 & 0 & 0 & 0 & 0 \\
K2.ISH & 20 & 0 & 0 & 6 & 26 \\
TRN1 & 0 & 20 & 1 & 0 & 21 \\
TRSH & 0 & 0 & 19 & 1 & 20 \\
TR.JSS.1 & 0 & 0 & 0 & 13 & 13 \\
Total & 20 & 20 & 20 & 20 & 80 \\
\hline
\end{tabular}

(d)

\begin{tabular}{ccccc}
\hline CLASS & Prod. Acc. & User Acc. & Prod. Acc. & User Acc. \\
\hline K2.ISH & (Percent) & (Percent) & (Pixel) & (Pixel) \\
TRN1 & 100 & 76.92 & $20 / 20$ & $20 / 26$ \\
TR.JSS.1 & 100 & 95.24 & $20 / 20$ & $20 / 21$ \\
TRSH & 95 & 95 & $19 / 20$ & $19 / 20$ \\
\hline
\end{tabular}

SAM overall accuracy $=(78 / 80) 97.5000 \% \_$SAM kappa coefficient $=0.9667$. 
(e)

\begin{tabular}{cccccc}
\hline CLASS & K2.ISH & TRN1 & TR.JSS.1 & TRSH & Total \\
\hline Un clasified & 0 & 0 & 0 & 0 & 0 \\
K2.ISH & 20 & 0 & 0 & 0 & 20 \\
TRN1 & 0 & 19 & 0 & 1 & 20 \\
TR.JSS.1 & 0 & 1 & 20 & 0 & 21 \\
TRSH & 0 & 0 & 0 & 19 & 19 \\
Total & 20 & 20 & 20 & 20 & 80 \\
\hline
\end{tabular}

MAXIMUM LIKELHOOD CLASSIFICATION overall accuracy $=(76 / 80) 95.0000 \%$.

(f)

\begin{tabular}{ccccc}
\hline CLASS & Prod. Acc. & User Acc. & Prod. Acc. & User Acc. \\
\hline K2.ISH & (Percent) & (Percent) & (Pixel) & (Pixel) \\
TRN1 & 100 & 100 & $20 / 20$ & $20 / 20$ \\
TR.JSS.1 & 95 & 95 & $19 / 20$ & $19 / 20$ \\
TRSH & 100 & 95.24 & $20 / 20$ & $20 / 21$ \\
\hline
\end{tabular}

MAXIMUM LIKELHOOD CLASSIFICATION kappa coefficient $=0.9430$.

(g)

\begin{tabular}{cccccccccc}
\hline CLASS & Limestone & \multicolumn{2}{c}{ Nayband Sandstone Dolomit } & Olr & Gd & Acidic & Mediate & Total \\
\hline Un clasified & 0 & 0 & 0 & 0 & 1 & 0 & 0 & 0 & 1 \\
Limestone & 10 & 0 & $10 / 10$ & 0 & 0 & 0 & 0 & 0 & 10 \\
Nayband & 0 & 10 & $10 / 10$ & 0 & 0 & 0 & 0 & 0 & 10 \\
Sandstone & 37 & 32 & $10 / 10$ & 0 & 0 & 0 & 0 & 0 & 0 \\
Dolomit & 93 & 35 & $10 / 10$ & 10 & 0 & 0 & 1 & 0 & 11 \\
Olr & 0 & 0 & 910 & 0 & 0 & 0 & 0 & 0 & 9 \\
Gd & 0 & 0 & $9 / 10$ & 0 & 9 & 9 & 0 & 0 & 9 \\
Acidic & 0 & 0 & $8 / 10$ & 0 & 0 & 0 & 8 & 0 & 8 \\
Mediate & 0 & 0 & $10 / 10$ & 0 & 0 & 1 & 1 & 10 & 10 \\
Total & 10 & 10 & $10 / 10$ & 10 & 10 & 10 & 10 & 10 & 80 \\
\hline
\end{tabular}

(h)

\begin{tabular}{ccccc}
\hline \multirow{2}{*}{ CLASS } & Prod. Acc. & User Acc. & Prod. Acc. & User Acc. \\
\cline { 2 - 5 } & (Percent) & (Percent) & (Pixel) & (Pixel) \\
\hline Limestone & 100 & 100 & $10 / 10$ & (Percent) \\
Nayband & 100 & 100 & $10 / 10$ & $10 / 10$ \\
Sandstone & 100 & 100 & $10 / 10$ & $10 / 10$ \\
Dolomit & 100 & 90.91 & $10 / 10$ & $10 / 10$ \\
Olr & 90 & 100 & 910 & $10 / 11$ \\
Gd & 90 & 100 & $9 / 10$ & $9 / 9$ \\
Acidic & 80 & 100 & $8 / 10$ & $9 / 9$ \\
Mediate & 100 & 83.33 & $10 / 10$ & $10 / 12$ \\
Total & 100 & 100 & $10 / 10$ & $10 / 10$ \\
\hline
\end{tabular}


Software, At the last step of flowchart of provided processing algorithms, the gathered data were combined with each other by putting layers prepared from different processing methods on each other using GIS10.02 Environment and faults and surface geological maps of study region were drawn. Figure 12 represents the faults map of the region which has been overlayed on IRS-PAN image. The faults maps have been prepared through comprising with Lineaments map of the region, with satellite images and removing the roads, waterways and folds. The diagram below the map indicates faults orientation toward the North in Zefreh region.

Figure 13 represents the final geological map of the ground's surface in $\mathrm{Ze}$ freh region has been prepared by combining results obtained from applying various types of used processing methods in present study on ASTER, LANDSAT8 and IRS-PAN images.

\section{Conclusions}

The geological map from the surface of under study area was prepared using remote sensing data with an acceptable accuracy to compare to the map with scale of 1:25,000. In addition the fault maps of the region which prepared automatically are in accordance with Earth fact. The matter indicates the capability of proposed flowchart of present study to surface geological mapping.

At the end of this article, considering input data, we examine the operation of

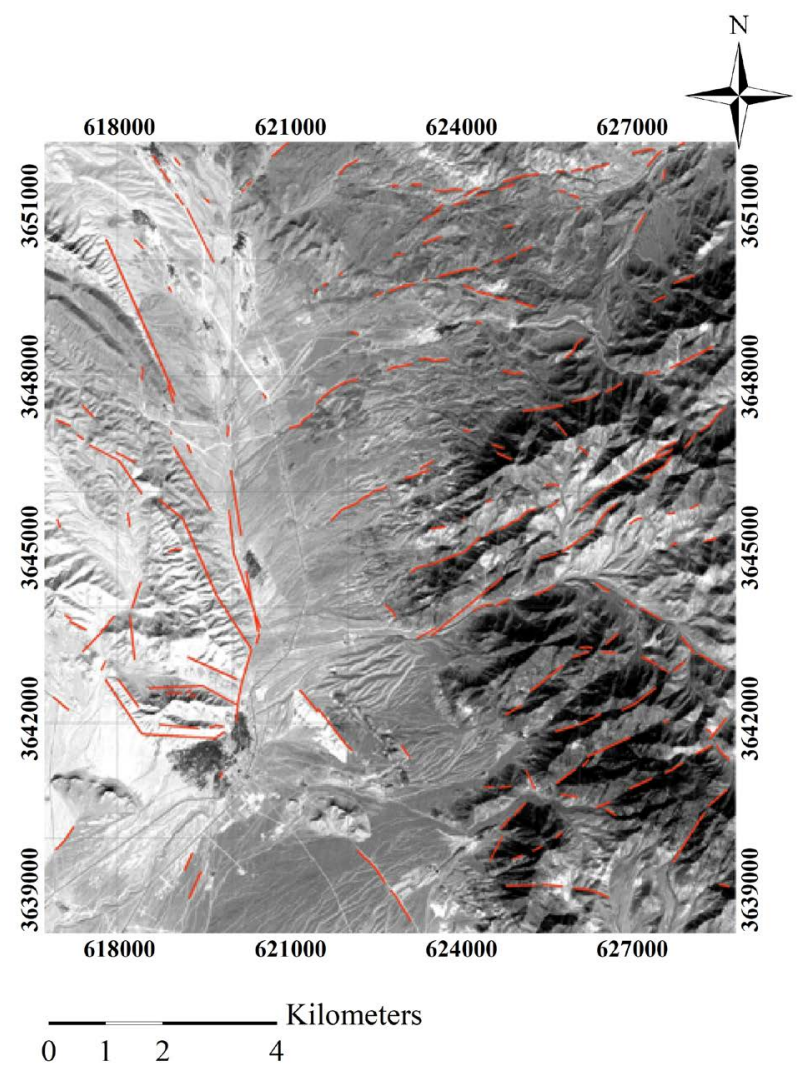

Figure 12. The Faults map extracted from Lineaments map. 


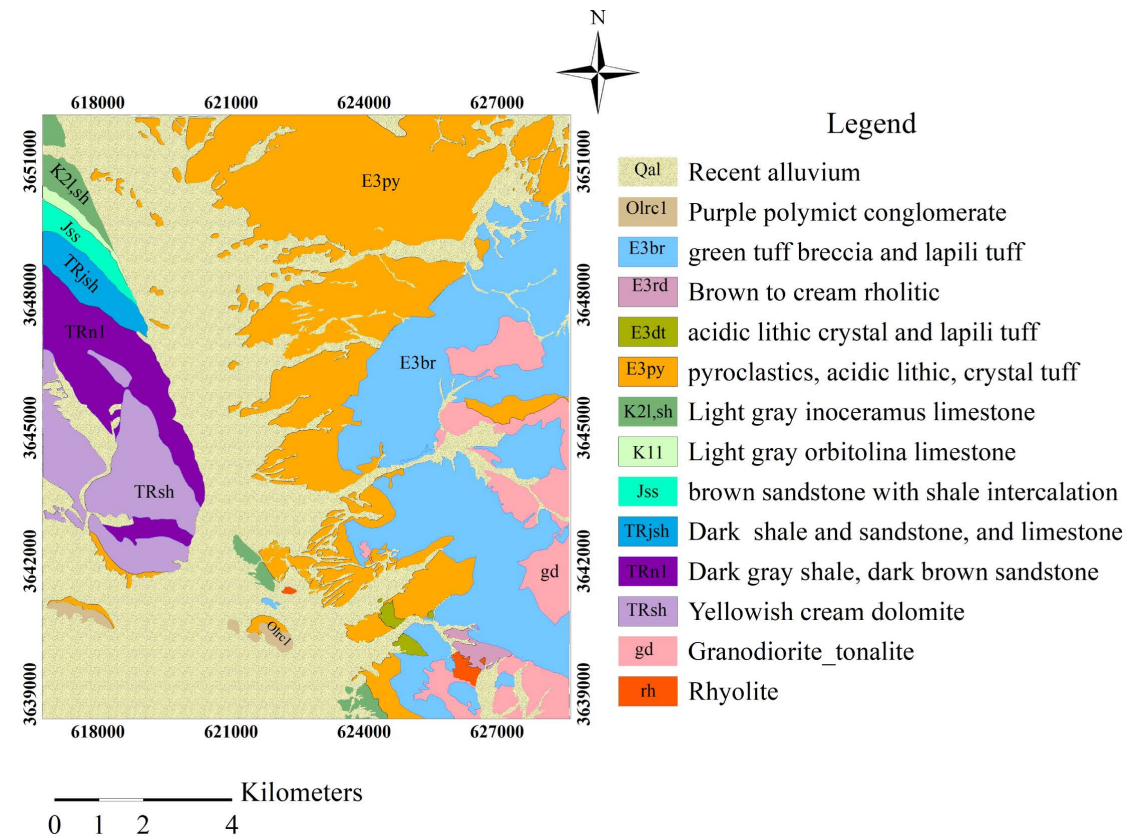

Figure 13. Final geological map of the Earth's surface in Zafreh region prepared by using satellite data of ASTER, LANDSAT8 and IRS-PAN.

the algorithms used in this research in the processing of remote sensing images to extract useful information in the preparation of a geological map.

The algorithm of principal component analysis (PCA) is a useful method to separate noises and duplicated data from spatial information in separated data packages, which has been also utilized in minimizing noise algorithm. It is also proper to create false color composites with the least amount of duplicated information. According to the fact that false color composites and band ratio are used to emphasize on certain effects and are not directly posed in numerical methods of information extraction, utilizing from the technique significantly helped to visual lithology separation of the region. As it is clear in the images and obtained results, most of the units of images have been separated from each other by this method. In this method to obtain the best results, it would be proper to identify desired effect at first and investigate it in the term of spectrum and then to determine its reflective and absorption bands and based on it, the bands related to reflection and absorption ranges of target effect used in proper sensors with higher spectral resolution in the range of absorption and reflection. In preparing PAN-SHARP images, the Gram-Schmidt Conversion was identified as the most proper method of combining images in present study. The results obtained from this conversion had lower noise and better visual quality compare to other methods of image conversion.

The results of applying maximum likelihood classification on data indicated the matter that LANDSAT8 data are more capable to pixel base classifying compare to ASTER data which is probably due to the high spectral resolution of ASTER data. In lithology with high percentage of material mixing, each pixel of 
image reflects different spectrums from itself. The matter led that the algorithm didn't classify most of the pixels in related class after introducing training samples. But implementing the technique with LANDSSAT8 image classifies units with mixed material more proper than basic spectrum classification methods. However, it is needed to prepare and exact training samples from all parts of geological units with differences in color tone to achieve optimum results. The validation procedure table of this method was prepared using OLI satellite image which indicates classification accuracy of $94 \%$ and kappa coefficient of 0.9430 and hence, explains the proper accuracy of this method in image classification.

To implement spectrum base algorithms, the images of ASTER were used due to having high spectral resolution. The image was also used to prepare spectral library, because utilizing from this image provides better results in output of classification methods compare to the standard libraries. The reason of this matter is that slight changes in the composition of the minerals cause different spectral signature. To select spectral diagram from pure pixels, the PPI index was used which comprising the obtained results with geological map of the region and 1:250,000 scales indicate the medium accuracy of this method in identifying pure pixels. The method is not able to identify all pure pixels of image, especially pixels related to the rock units with mixed materials. But it is more proper in identifying uniform units.

The advantage of SAM method compare to other spectral classification methods is ease and speed of its implementation. However, all of the basic spectrum algorithms have disadvantages in identifying and classifying mixed units due to the nature of these methods. The results obtained from LSU algorithm indicate the distinguishing feature of this method compare to other basic spectrum algorithms in the tem of mixed lithology separation which is relatively impossible in other basic spectrum algorithms. However, obtaining accurate results by this method needs complete understanding of the geology of under study region to be able to separate desired member from other areas correctly in post-processing step. Spectral fitness factor (SFF) is a spectral classification method in which the spectrums inserted to the algorithm get threshold to make it possible for each spectrum to get a special signature through slight differences in similar spectrums. The nature of this algorithm is similar to Sam, but its implementing is more complex compare to other basic spectrum classification methods. However, the method is more sensitive to spectral mixture. It means that, the method provides acceptable responses only in the case of using for pure and uniform units and provides no acceptable response in the case of impurity in considered unit. The results obtained from determining the accuracy of classified images with basic spectrum methods indicate overall accuracy of $86.25 \%$ and Kappa coefficient of 0.8167 to spectral fitness basic pixel classification, overall accuracy of $90 \%$ and Kappa coefficient of 0.8667 to LSU classification and overall accuracy of $97.5 \%$ and Kappa coefficient of 0.9667 to spectral angel mapping method. The matter indicates high accuracy of Sam method in image classification compare to other basic spectrum classification methods. However, it is possible that 
different results are obtained in different regions and other methods show higher accuracy. The method of automatically extracting lineaments in GEOMATICA Software significantly accelerates lineaments mapping. To input of this algorithm, Images such as Hill-shade and IR-PAN are used in which the edges are visible. The method extracts all linear effects of the image such as waterways, roads and faults, which its results must be modified, based on the desired purposes and other linear effects used in lithology mapping and preparing final lineaments map.

In the case of utilizing from data with higher spatial and spectral resolution compare to the data have been used in present study, more accurate results would be obtained.

\section{Acknowledgements}

This article was carried out as part of the author's M.Sc. thesis in Geological Remote Sensing at Isfahan (Khorasgan) Branch, Islamic Azad University, Isfahan, Iran.

\section{References}

[1] Hairapetian, V., et al. (2016) Geological Index Map of Iran, 125:000 Series, Zefreh. Geological Survey Geological Survey and Mineral Exploration Organization of Iran, Isfahan.

[2] Aronoff, S. (2005) Remote Sensing for GIS Managers. ESRI Press, 524.

[3] Gebbinick, M.K. (1998) Decomposition of Mixed Pixels in Remote Sensing Images to Improve the Area Estimation of Agricultural Fields.

[4] Abrams, M. and Hook, S. (2000) ASTER User Handbook. Version 2, Jet Propulsion Laboratory.

[5] U.S. D. o. t. Interior (2016) Landsat 8 (L8) Data Users Handbook, South Dakota.

[6] Green, A.A., Berman, M., Switzer, B. and Craig, M.D. (1988) A Transformation for Ordering Multispectral Data in Terms of Image Quality with Implications for Noise Removal. IEEE Transactions on Geoscience and Remote Sensing, 26, 68-74. https://doi.org/10.1109/36.3001

[7] Boardman, J. (1993) Automating Spectral Unmixing of AVIRIS Data Using Convex Geometry Concepts, In: Summaries of the 4th Annual JPL Airborne Geoscience Workshop, 11-14.

[8] Zhang, X., Pamer, M. and Duke, N. (2007) Lithologic and Mineral Information Extraction for Gold Exploration using ASTER Data in the South Chocolate Mountains (California). ISPRS Journal of Photogrammetry and Remote Sensing, 62, 271-282.

[9] Sultan, M., Arvidson, R.E., Sturchio, N.C. and Guinnes, E.A. (1987) Lithologic Mapping in Arid Regions with Landsat TM Data: Meatiq Dome, Egypt. Geological Society of America Bulletin, 99, 748-762. https://doi.org/10.1130/0016-7606(1987)99<748:LMIARW>2.0.CO;2

[10] Adam, J.B. and Felic, A.L. (1967) Spectral Reflectance 0.4-2.0 Micron of Silicate Rock Powders. Journal of Geophysical Research, 72, 5705-5715. https://doi.org/10.1029/JZ072i022p05705

[11] Gad, S. and Kusky, T. (2006) Lithological Mapping in the Eastern Desert of Egypt, the Barramiya Area, using Landsat Thematic Mapper (TM). Journal of African 
Earth Sciences, 44, 196-202.

[12] Oommen, T. (2008) An Objective Analysis of Support Vector Machine Based Classification for Remote Sensing. Mathematical Geosciences, 40, 409-424.

https://doi.org/10.1007/s11004-008-9156-6

[13] Richards, J.A. (1993) Remote Sensing Digital Image Analysis. Springer-Verlag, Heidelberg. https://doi.org/10.1007/978-3-642-88087-2

[14] Boardman, J.W., Kruse, F.A. and Green, R.O. (1998) Mapping Target Signatures via Partial Unmixing of AVIRIS Data. JPL, 23-26.

[15] Kruse, F.A., Boardman, J.W., Lefkoff, A.B., Heidebrecht, K.B., Shapiro, A.T., Barloon, P.J. and Goetz, A.F.H. (1993) The Spectral Image Processing System (SIPS) Interactive Visualization and Analysis of Imaging Spectrometer Data. Remote Sensing of Environment, 44, 145-163.

[16] Perry, D. (2000) Visual and Near-Infrared Imagery Using NVIS, California.

[17] Green, A.A. and Craig, M.A. (1985) Analysis of Aircraft Spectrometr Data with Logarithmic Residuals. JPL Publication, 111-119.

[18] Ghafori, A. (2006) Careful Management of Traditional Agriculture with Help of Sub-Pixel Classification.

[19] Landgrebe, D. (1999) Some Fundamentals and Methods for Hyperspectral Image Data Analysis.

[20] Matkan, A.A. and Kazemi, A. (2009) Using RS and GIS for Considering Cadmium Distribution and Polluted Vegetation in Esfahan Province. Environmental Sciences, 65-76.

[21] Alhirmizy, S. (2015) Automatic Mapping of Lineaments Using Shaded Relief Images Derived from Digital Elevation Model (DEM) in Kirkuk Northeast Iraq. International Journal of Science and Research, 4, 2228-2233.

[22] Muhammad, M.M. and Awdal, A.H. (2012) Automatic Mapping of Lineaments Using Shaded Relief Images Derived from Digital Elevation Model (DEM) in Erbil-Kurdistan, Northeast Iraq. Advances in Natural and Applied Sciences, 138-146.

[23] Abdullah, A., Juhari Mat, A. and Abdullah, I. (2010) Automatic Mapping of Lineaments using Shaded Relief Images Derived from Digital Elevation Model (DEMs) in the Maran-Sungi Lembing Area. EJGE, 15, 949-957. 